\title{
Local Cable Operator And Telecom Operator Partnership For Broadband Growth In India
}

T.P. Pavan Kumar (E-mail: pavan@91call.com), Qatar Telecom, Qatar

\begin{abstract}
This paper discusses the present state of Broadband in India. It looks at various factors for the low penetration and initiatives by the Regulator and Industry to achieve higher growth. It brings in new thought of Local Cable Operator (LCO) and Telecom Operator (TELCO) Partnership to achieve accelerated growth.
\end{abstract}

\section{BROADBAND IN INDIA TODAY - AN INTRODUCTION}

C ndia continues to witness significant growth in telecom subscriber base over the past five years with the tele-density reaching 11.43 in Dec.2005(1). The target to achieve tele-density of 15, set by the National Telecom Policy of 1999, is all set to become reality well ahead of time. This phenomenal growth is triggered by the entry of private TELCOs, rapid expansion of telecom infrastructure, steep fall in telecom tariffs and friendly Government Policies. While the phenomenal growth in Tele-density is a success story, the Broadband penetration lags far behind the target set by the Broadband Policy of 2004. The Broadband subscriber base stood at 0.84 million in Dec.2005 against the target of 3.0 million. India is among the world's lowest Broadband penetration nations and does not find a place among the top 10 Broadband Penetration nations in Asia-Pacific.

For India, a fast emerging knowledge based economy by its highly skilled technical and IT manpower, this is an area that requires immediate attention. A pragmatic approach is essential to achieve higher penetration and accelerated growth of Broadband. This will not only bridge the digital divide but will also create new entrepreneurial opportunities for the youth of the country.

The Telecom Regulatory Authority of India (TRAI) has set a target of 20 Million Broadband subscribers (1.7 percent penetration) by 2010. It has recommended setting up of National Internet Exchange(NIXI), amendment of DTH \& VSAT regulations to offer Broadband Services, allowing availability of low cost access devices, decreasing duty on imported Broadband equipment, Un-bundling of BSNL(Incumbent Telecom Operator) last-mile for DSL services, exemption of service tax for Internet Service Providers(ISPs), tax free allowance to public and private sector employees for Broadband Access at home, de-licensing of 2.40-2.48 GHz frequency to setup low power wireless networks etc..

The "India's Broadband Economy: Vision 2010", a study conducted by IBM Business Consulting Service on behalf of Confederation of Indian Industry (CII) and Ministry of Communications \& Information Technology (MCIT) indicates that the present value (2004) benefit for the Indian Economy due to the growth in Broadband is expected to be USD 90 Billion for the period 2010-2020, with an 11 percent additional growth in the labor productivity. It further says that it is expected to launch new business lines and increased efficiency in existing businesses, leading to direct employment of 1.8 million and total employment of 62 million by 2020 .

The CII study assumes availability of always on $1.5 \mathrm{Mbps}$ of Broadband Service while the TRAI Model defines Broadband as always on $256 \mathrm{Kbps}$ and de-links Broadband TV to achieve higher penetration in price sensitive household customers. The TRAI feels that of the five modes of access namely copper loop, cable TV network, 
terrestrial wireless access, satellite communication, and fiber to the home or to the building/community center, DSL on copper will play a significant role in driving Broadband growth in India.

\section{WHY SLOWER GROWTH AND PENETRATION - AN ANALYSIS}

The causes for the slower growth of Broadband in India can be attributed to high cost of Personal Computers and Internet access, poor telecom and internet infrastructure, limited digital content in local languages, slow growth of e-commerce, lack of e-governance initiatives by the Government etc.

The Indian Computer market continues to be protected with restrictions on import of used and low Cost PCs. The domestic market still relies on the imported hardware and components making the overall cost of PCs over Rs.15,000/-, making it expensive for an average household. Though the Government had brought down the Customs duty on computer hardware, high local taxes make the PC expensive. With the introduction of compulsory Computer Education at the schooling level, there is a clear case for the Government to introduce zero tax on PCs purchased by the household. Also, concessions in the form of tax holiday must be given to the SOHO and SME segment for investments in office automation.

India has witnessed an internet revolution in the urban areas soon after the introduction of these services in Aug.1995; the user base has grown to 6.13 million at the end of 2005. Though the ISPs entered this business with high expectations, their presence is limited to top 20 to 25 cities of the country. This industry lacks infrastructure, private investment and Government support. Top players like Wipro and Satyam had to withdraw from this business due to unviable market environment and sluggish growth. Of the 590+ ISP licensees, only 129 are operational as In Sept. 2005. The cost of internet access continues to be high at over Rs.10/hour, beyond the affordability of an average household. The lower PC penetration and poor telecom infrastructure beyond major cities has effected the growth of this industry. In the recent times, some of the ISPs have started addressing the household, SOHO and SME segments through channel partners who setup Local Area Network(LANs) within a locality(geographical area) and provide Broadband service. Customers pay the setup fee to cover the cost of LAN cabling and monthly subscription fee, based on the choice of package. This model, though successful to a certain extent, does not bring in higher subscriber numbers and is limited to the urban areas.

Though India has achieved significant growth in tele-density, the Telecom infrastructure continues to be limited to urban and semi-urban areas. The growth in mobile subscribers is far higher compared to the wire line. In 2005, the mobile subscribers grew by 58.13 percent, while the wire line has registered a subdued growth of $9.0 \%$ (1). The private players continue to focus on expanding mobile infrastructure that can deliver voice and value added services of limited bandwidth. Higher cost of infrastructure, lower Average Revenue per User (ARPU) and subdued growth are discouraging private investments in wire line. BSNL, the incumbent operator, continues to be the sole provider of wire line services in most of the urban, semi-urban and rural areas. Its network suffers from out dated technology and can deliver Broadband services in limited parts of the country.

Globally, Broadband is increasingly being used for new applications like Gaming, Entertainment, Video on Demand, Video Chat etc.. The availability of these content rich services is triggering the demand for higher bandwidth and Subscriber growth. Availability of digital content in local language is a pre-requisite to achieve wider acceptance and faster growth of Broadband. This is demonstrated by the growth achieved by countries like China, Korea and Japan that have build the digital content in local languages. This has helped these nations to achieve faster Broadband growth, bridge the digital divide and penetrate into the rural areas. South Korea leads in Asia-Pacific region with 24.23 percent penetration and China despite English language barrier has 6.67 percent penetration with annual growth of over 90 percent (2). India is far behind in developing digital content and applications in local languages targeted at Broadband Customers.

The major economies around the Globe benefited with the introduction of eGovernance services that created citizen convenience and triggered faster growth of Broadband, South Korea being a classic example. India is yet to see such initiatives either from the Central and State Governments. The need and demand for such initiatives is demonstrated by the success of eGovernance services launched by the Govt. of Andhra Pradesh called 'eSeva 
services'. This facilitates the citizens to pay utility bills, renew licenses, pay taxes, register birth $\&$ death etc.. The success of this initiative is reflected by the 46 million transactions done through eSeva centres across the State and 1.2 million transactions done online since its inception in Aug. 2001. In addition to citizen convenience, eSeva has created entrepreneurial opportunities for many youth by opening franchisee centres in the State. Similar initiatives by the Central and State Governments will unlock huge potential for growth of Broadband and create entrepreneurial and employment opportunities for the youth of India.

\section{CABLE TV IN INDIA - A SUCCESSFUL MODEL}

The Local Cable Operator (LCO) has transformed the Indian television industry and played a crucial role in achieving exponential growth since its inception in 1991. Cable TV entered India with the live broadcast of Gulf War by CNN in 1991. The number of Cable TVs in India has grown from 1.2 Million in 1992 to 38 Million in 2002 (IRS Survey, 2002). With over 250 channels, Indian Cable TV is one of the fastest growing industries in the world. Increased affordability, drop in TV prices \& growth of regional channels is increasing the penetration of Cable TV in semi-urban and rural areas. As per the industry estimates, the Cable \& Satellite TV is expected to reach 75 million homes by 2008 and 94 million by 2010. This is supported by the study of Ernst \& Young, projecting the growth of Indian entertainment industry at a compound annual growth rate (CAGR) of 17 per cent to $\$ 9.4$ billion by 2008 .

The Cable TV distribution started in urban areas as an unorganized individual dish antenna based system and matured into an organized Multi System Operator (MSO) operations with head-ends being setup in many of the cities and towns with population of over 100,000. The MSOs lay optic fiber network across their coverage area to connect the LCOs. The MSOs are moving up the value chain in the major cities of India by setting up infrastructure to deliver digital content on demand like movies \& songs, setting up localized interactive channels, offering internet services and broadcasting live major local events like State Assembly Session, Festivals, Processions, Agitations, and Demonstrations etc. The MSOs charge the individual LCOs monthly subscription fee in the range of Rs. 45 to Rs.60 per subscriber in the major towns and Rs.30 to Rs. 45 per subscriber in the smaller towns.

The LCO owns and manages the cable network connecting to the individual homes within a locality (limited geographical area) and takes care of service delivery and customer support. The LCO servicing the household has 450/550 MHz coaxial copper cables that can deliver up to 55 channels and have a subscriber base of around 500 in Cities and 250 in smaller towns. The distribution of Cable Network to household in a locality continues to be the monopoly of one single LCO and he does not allow a second operator to lay the Cable or service the Customer. The LCO collect subscription fee in the range of Rs. 150 to Rs. 200 per month in the major cities/ towns and in the range of Rs.75 to Rs. 100 per month in the smaller towns and villages. Some of the LCOs are upgrading their cable systems to carry bi-directional signals in order to provide Internet Access. The LCOs in smaller towns, mandals \& villages, with population less than 10,000, manage their own dish antennas to receive satellite signals and distribute them to the individual household. They typically distribute up to 25 free-to-air channels. Most of these LCOs have subscription base of up to 200, distributing free to air channels and do not have the equipment nor customer base to subscribe to the pay channels.

The MSOs and LCOs have fiber and copper networks running into millions of Kms, connecting millions of household across India. The quality of service, reliability, and uptime of these networks is a well-proven model. This model has enabled faster growth of satellite television industry, penetrating into the rural areas of India. Though the ARPUs are lower at Rs.100-Rs.150 per month, the MSOs and LCOs continue to reap good profits due to lower infrastructure and operational costs. Some of the LCOs have upgraded their cable network to be bi-directional and started offering internet services. This has limitations due to high cost of cable modem and lack of skills on part of LCOs to address internet service related issues.

The cost to setup last-mile infrastructure for a subscriber is far higher for the TELCO compared to the LCO. The TELCO lays buried cables, pay restoration charges to the Government and take longer time to build the last mile network. On the contrary, the LCO runs the aerial cable and does not need specific approval from Government or pays charges. Hence, for the LCO the setup cost is far lower compared to a TELCO. Being limited to a smaller area, the LCO is well positioned and equipped to support his customers. 


\section{A NEW APPROACH - LCO AND TELCO PARTNERSHIP}

As we grapple to find ways and means to achieve higher Broadband growth, the one Player who can really make this happen is the Local Cable Operator (LCO). The best model to achieve higher broadband growth and penetration into semi-urban and rural markets would be the through TELCO and LCO Partnership. TELCOs have their network reaching Towns and Mandals but lack distribution network to reach individual customers. LCOs are best placed to fill this gap by utilizing existing cables or by laying new cables to reach individual customers at a very economical cost. In the partnership model, The TELCO delivers the broadband services at central site of LCO and LCO will distribute and manage the services. The TELCO can train and upgrade the knowledge and skills of the LCOs to distribute and mange Broadband services, there by eliminating the need to setup dedicated support services. Many of the TELCO in India already have digital content and this partnership will expand the market and bring in new stream of revenues. The TELCO, due to their size of operation and national reach are best placed to offer internet bandwidth services at cheaper price compared to ISPs. This partnership can help India in leap-froging the growth of Broadband that is very essential not only to sustain but to achieve higher economic growth.

\section{REFERENCES}

1. International Telecommunication Union - Broadband Korea: Internet Case Study, Mar.2003.

2. TRAI Press Release No. 3/2006.

3. World Broadband Research Report - 2005 Q3 by Telecompaper

\section{NOTES}

